\title{
Percepção e uso dos insetos pelos moradores da comunidade do Ribeirão da Ilha, Santa Catarina, Brasil
}

\author{
Mônica Antunes Ulysséa ${ }^{1 *}$ \\ Natalia Hanazaki ${ }^{2,3}$ \\ Benedito Cortês Lopes ${ }^{2,4}$

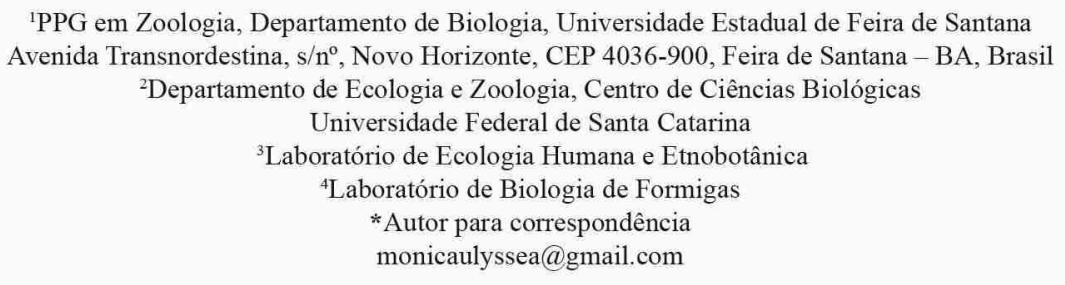

Submetido em 01/11/2009

Aceito para publicação em 16/04/2010

\section{Resumo}

Este trabalho apresenta a percepção que os moradores do Ribeirão da Ilha, Florianópolis, Ilha de Santa Catarina, têm sobre os insetos e os distintos usos dados a estes animais. O estudo foi realizado entre agosto e outubro de 2007, por meio da aplicação de entrevistas semi-estruturadas com 50 moradores da comunidade. A etnocategoria inseto é formada por 16 animais, como abelha, barata, besouro, aranha e cobra, dentre outros. Além disso, é majoritariamente constituída por animais percebidos negativamente pela população, isto é, que causam sensações como medo e nojo. O conhecimento sobre os usos dos insetos é amplo e está ligado ao uso lúdico, decorativo, alimentício, medicinal, à previsão do tempo e à obtenção de dinheiro. Atualmente, apenas três usos são praticados pela comunidade: consumo de mel na alimentação, picada de abelha para curar reumatismos e borboleta para decoração.

Unitermos: conhecimento tradicional, etnoentomologia, etnotaxonomia

\section{Abstract}

The perception and use of insects by the residents of Ribeirão da Ilha, Florianópolis, SC, Brazil. This work presents the perception of the residents of Ribeirão da Ilha, Florianópolis, Santa Catarina Island, about the insects and the distinct uses made of them. The study was carried out between August and October of 2007 through semi-structured interviews with 50 residents of the community. The ethnocategory 'Insect' is composed by 16 animals such as bees, cockroaches, beetles, spiders, snakes and others. This category is mostly seen negatively by the local population, or causes a sensation of fear and disgust. The knowledge about the use of insects is wide and it is related with ludic, decorative, alimentary and medicinal usages, as well as with forecasting the weather and earning money. However, nowadays only three uses are practiced by the community: consumption of honey in food, employment of bee stings to cure rheumatism, and butterflies for decoration.

Key words: ethnoentomology, ethnotaxonomy, local knowledge 


\section{Introdução}

A Etnociência pode ser definida como a etnografia de saberes do outro, construída a partir de referenciais de disciplinas da academia (D'Olne Campos, 2002). A partir deste conceito pode-se estabelecer que a Etnobiologia atua no espaço de interação das populações humanas com os diversos recursos naturais dos ecossistemas que as incluem, buscando entender as atitudes culturalmente estabelecidas a partir deste contato, conferindo atenção especial aos processos de percepção, conhecimento e usos (Posey, 1987a).

$\mathrm{O}$ conhecimento biológico tradicional pode ter maior ou menor valor para determinado grupo humano de acordo com as características deste grupo, isto é, dependerá dos tipos de empregos dados ao recurso, da frequência do uso, da possibilidade de uso múltiplo e de se obter benefícios, tanto econômicos quanto de subsistência e, além disso, do simbolismo que este possa apresentar (Pagaza-Calderón et al., 2006).

As noções e os saberes coletivos de uma comunidade sobre a biodiversidade de seu mundo imediato estão intimamente ligados à maneira de pensar, sentir e atuar em relação aos componentes desta diversidade (CostaNeto, 2002).

Neste contexto, a Etnoentomologia pode ser compreendida como sendo o estudo dos conhecimentos dos Homens sobre os insetos ou, parafraseando Costa Neto (2000b), "a Etnoentomologia pode ser definida como o estudo transdisciplinar dos conhecimentos, das crenças, dos sentimentos e dos comportamentos que intermediam as relações entre as populações humanas que os possuem e o mundo dos insetos".

Os insetos são o grupo animal com o maior número de espécies existente, cerca de 1 milhão, e estão presentes em praticamente todos os ecossistemas, tendo participação em processos ecológicos fundamentais como: ciclagem de nutrientes, dispersão de fungos, polinização das plantas com flores, dispersão de sementes, fonte direta de alimento para vários animais, controle de populações de plantas por meio da herbivoria e de animais pela da dispersão de doenças, predação e parasitismo etc (Gullan e Cranston, 2008).
Por sua grande abundância e distribuição, os insetos estão sempre presentes na vida das pessoas nas mais variadas situações e são estas experiências particulares que, possivelmente, irão afetar o julgamento e a percepção delas sobre estes animais. A acumulação destas percepções e a troca das mesmas entre as pessoas da comunidade irão direcionar o tipo de atitude a ser estabelecido entre estas e os insetos (Ellen, 1997; Goodenough, 2003). Em todo o mundo existem referências de que o grupo dos insetos está presente no pensamento mágico de muitas culturas e tem sido integrado a diversas tradições (Navarijo, 2006). CostaNeto (2004) destaca que, na antiguidade, a visão geral dos insetos era construída com base na vivência pessoal ou de um grupo, associada à falta de informações precisas sobre estes animais. Hoje, a construção desta percepção está mais intimamente relacionada com a abordagem estabelecida pela mídia ao tratar destes animais e também pela perda da vivência, ou seja, pelo distanciamento entre Homem e inseto. Longo e Pires (1998), analisando a percepção de estudantes em relação à fauna, perceberam que em grandes cidades como São Paulo a mídia, mais que o próprio meio natural, é um importante veículo para se obter informações sobre a natureza. E, por esta mídia mostrar cotidianamente que os insetos devem ser exterminados, esses animais são mais notados que outros, porém sempre com uma conotação negativa.

Costa-Neto (2000a) reflete sobre o fascínio provocado pelos insetos à espécie humana, apresentando diversos campos nos quais se pode encontrar a influência desta relação, tais como: música, literatura, linguagem, teatro, cinema, alimentação (entomofagia), medicina (entomofobia e entomoterapia), artes plásticas, artes gráficas, entretenimento (circos de pulgas e rinhas de louva-a-deus), sexualidade, filosofia, religião, folclore e medicina popular.

O objetivo deste estudo foi de registrar a percepção e uso dos insetos pelos moradores da comunidade tradicional do Ribeirão da Ilha.

\section{Material e Métodos}

\section{Área de estudo}

O distrito do Ribeirão da Ilha está localizado no sudoeste da Ilha de Santa Catarina, SC/Brasil e possui 
uma área total de $51,54 \mathrm{~km}^{2}$. O estudo foi realizado nas três localidades mais antigas do distrito: Barro Vermelho, Freguesia do Ribeirão da Ilha e Costeira do Ribeirão ( $27^{\circ} 43^{\prime} 46^{\prime \prime} \mathrm{S}$ e $\left.48^{\circ} 33^{\prime} 37^{\prime \prime} \mathrm{W}\right)$, abrangendo 666 casas (número determinado em uma saída de campo na qual se percorreu toda a área).

Atualmente, a comunidade do Ribeirão da Ilha totaliza 18.586 habitantes, $5,86 \%$ da população da Ilha (IBGE, 2000). Hoje, o local é conhecido nacionalmente pela atividade de cultivo de ostras e mariscos, iniciada por volta de 1995. Mesmo com as alterações mais recentes, a localidade ainda conserva características da presença açoriana, no linguajar, na confecção da renda de bilro, na manutenção de costumes tradicionais como a Folia dos Reis e a Festa do Divino Espírito Santo, e na arquitetura das casas e da Igreja Matriz (IPUF, 2007).

\section{Metodologia}

A coleta de dados foi efetuada por meio de entrevistas com os moradores das três localidades mais antiga do Ribeirão da Ilha, realizadas de agosto a outubro de 2007. O grupo amostral foi constituído por moradores que residiam há mais de 40 anos no local e que quiseram participar da pesquisa. A amostragem foi intencional utilizando-se a técnica "bola-de-neve", e as entrevistas foram baseadas em roteiros com perguntas semi-estruturadas (Albuquerque e Lucena, 2004). O roteiro foi estabelecido após seis entrevistas piloto realizadas em outras comunidades do bairro Ribeirão da Ilha. As questões foram todas abertas, com exceção daquelas referentes ao perfil do informante. Entrevistas semi-estruturadas com questões abertas são a forma mais indicada para a compreensão de sistemas de relações (Quivy e Campenhoudt, 1992). Isto porque podem ser exploradas de diversas formas adaptando-as a cada entrevistado, os quais podem dar ênfase a determinado tema dentre os vários abordados.

Além disso, a metodologia escolhida valoriza uma perspectiva qualitativa, pois trabalha com o universo de atitudes, ou seja, informações que não podem ser reduzidas à operacionalização das variáveis (Minayo, 2003). Porém, possui um viés quantitativo, na medida em que busca acessar a opinião de vários moradores por meio de entrevistas.
O roteiro das entrevistas foi dividido em três partes: o perfil dos informantes, a caracterização do grupo dos insetos e a observação de 28 imagens de animais, sendo 19 de insetos - abelha (Hymenoptera, Apis mellifera Linnaeus, 1758), barata (Blattaria, Periplaneta americana Linnaeus, 1758), besouro (Coleoptera, Scarabaeidae), bicho-pau (Phasmatodea), borboleta (Lepidoptera, Danaus plexippus Linnaeus, 1758), cigarra (Hemiptera, Cicada sp.), cupim (Isoptera, Nasutitermes sp.), esperança (Orthoptera, Tettigoniidae), formiga (Hymenoptera, Dinoponera australis Emery, 1901), gafanhoto (Orthoptera), joaninha (Coleoptera, Coccinella septempunctata Linnaeus, 1758), lagarta (Lepidoptera), libélula (Odonata), louva-a-deus (Mantodea), maria-fedida ou bicho frade (Hemiptera, Pentatomidae), marimbondo (Hymenoptera, Vespidae), mosca (Diptera, Musca domestica Linnaeus, 1758), pernilongo (Diptera) e paquinha (Orthoptera, Gryllotalpidae) - e nove imagens de animais não insetos - aranha (Araneae), cobra [Squamata, Serpentes, Micrurus corallinus (Merrem, 1820)], escorpião (Scorpiones), lagarto (Squamata, Sauria), minhoca (Oligochaeta, Haplotaxida), morcego (Chiroptera), piolho-de-cobra (Diplopoda), rato (Rodentia) e tatuzinho-de-jardim (Isopoda). Tanto na segunda quanto na terceira parte do roteiro, os informantes tiveram a oportunidade de citar usos empregados aos insetos. Os tipos de sensações que os informantes descreveram ter quando viam qualquer um destes 28 animais foram incluídos em categorias de percepção (positiva, negativa, neutra e respeito) de acordo com a intenção esboçada pelo informante por intermédio da fala e expressão facial.

As informações sobre os usos dados aos insetos foram analisadas em relação à fidedignidade (FL) e prioridade de ordenamento (ROP) (Friedman et al., 1986), obtidos por: $\mathbf{R O P}=\mathbf{F L} \mathbf{x} \mathbf{R P}$, onde RP é a popularidade relativa (número de informantes que citaram um dado inseto, dividido pelo número de informantes que citaram o inseto mais citado) e FL, dado em porcentagem, é obtido com a fórmula $\mathbf{I p / I u ~} \mathbf{x}$ 100. Nesta, Ip é o número de informantes que sugerem o uso de um determinado inseto para um uso principal e Iu é o número total de informantes que citaram o inseto. 


\section{Resultados e Discussão}

Dos 50 informantes que concordaram em participar da pesquisa, apenas seis não eram nativos da comunidade do Ribeirão da Ilha, mas moravam na localidade há 40 anos ou mais.

O perfil do grupo amostral foi constituído, em sua maioria, por mulheres aposentadas e/ou pensionistas com idade entre 71 e 80 anos cujo tempo de moradia na comunidade variou entre 61 e 80 anos. A média de idade encontrada foi de 69 anos, sendo o mais novo com 45 anos e o mais velho com 87 .

Muitas sociedades humanas incluem na etnocategoria inseto outros animais que não são considerados como insetos verdadeiros, isto é, os pertencentes à Classe Insecta proposta por Linnaeus (Cereto e Lopes, 2008). Na tentativa de caracterizar melhor o grupo dos insetos e seus representantes na visão dos moradores do Ribeirão da Ilha, na terceira parte do roteiro, os informantes classificaram as 28 imagens de animais. As categorias de classificação não foram pré-determinadas no roteiro, todas foram descritas a partir dos informantes.

Os insetos sob o ponto de vista da classificação científica, como abelha (Apis mellifera), barata (Periplaneta americana), besouro (Scarabaeidae), bicho frade (Pentatomidae), bicho-pau (Phasmatodea), esperança (Tettigoniidae), formiga (Dinoponera australis), lagarta (Lepidoptera), louva-a-deus (Mantodea), marimbondo (Vespidae), mosca (Musca domestica) e pernilongo (Diptera), foram classificados como pertencentes à etnocategoria insetos ${ }^{1}$ por $50 \%$ ou mais dos informantes (Tabela 1).

A borboleta (Danaus plexippus) e a libélula (Odonata) foram classificadas como insetos por $46 \%$ (23 entrevistados) e 34\% (17) dos informantes, respectivamente. Entretanto 52\% (27) dos informantes acreditam que a borboleta é um bicho/animal não inseto. Do mesmo modo, 40\% (20) deles consideraram a libélula um bicho/animal não inseto. De acordo com a classificação adotada pela maioria dos informantes,

1 No decorrer do texto a palavra inseto(s) quando em itálico faz referência a todos os animais pertencentes à etnocategoria inseto e quando grafada sem itálico diz respeito aos animais considerados dentro da categoria de classificação Insecta. tanto a borboleta quanto a libélula não fazem parte da etnocategoria inseto. Este fato pode estar associado com a percepção positiva e/ou neutra dos informantes com relação a estes dois insetos (Tabela 2). CostaNeto (2005), afirma que para a maioria das pessoas o grupo dos insetos é constituído por animais percebidos negativamente por aqueles e que os fazem experimentar certas sensações, como medo, nojo, agonia e irritação. Além da borboleta e da libélula, a cigarra (Cicada sp.) também foi classificada como bicho/animal não inseto por $56 \%$ (28) dos entrevistados (Tabela 1) e é percebida positivamente por $96 \%$ (48) deles (Tabela 2). Esta percepção positiva está relacionada com a alegria que os informantes disseram sentir ao ouvir o canto da cigarra: "A cigarra só traz alegria com seu cantar" (L., 79 anos).

Já o cupim (Nasutitermes sp.) não foi reconhecido por nenhum dos 50 informantes (Tabela 1). Isto, provavelmente, deve-se à confusão que existe entre as formigas com asas e os cupins. Os indivíduos reprodutores dos cupins, reis e rainhas, possuem asas e, em determinadas estações, são produzidos em grandes quantidades que deixam a colônia em enxames, acasalam-se e fundam uma nova colônia (Triplehorn e Johnson, 2005). Muitas pessoas costumam chamar estes cupins alados de formigas-de-asas devido à semelhança morfológica entre os dois insetos e, além disso, habitualmente caracterizam o cupim sem vê-lo, apenas pelo fato de encontrarem um pó marrom ou bege dentro ou embaixo dos móveis de madeira.

Dentre os outros animais não insetos que foram trabalhados durante as entrevistas, a aranha (Araneae), a cobra (Micrurus corallinus), o escorpião (Scorpiones) e o rato (Rodentia), foram classificados como insetos por $82 \%$ (41), 52\% (26), 50\% (25), 46\% (23) dos informantes, respectivamente (Tabela 1). Comumente, os informantes justificavam o fato de estes quatro animais serem considerados insetos por serem perigosos, venenosos ou transmitirem alguma doença. Costa-Neto (2004), registrou o mesmo resultado com relação às cobras na Serra da Jibóia/BA e Cereto e Lopes (2008), na comunidade do Pântano do Sul/llha de Santa Catarina, obtiveram os mesmos resultados para aranha, cobra e rato, demonstrando como é amplamente difundida a noção de que animais considerados nocivos para o homem são categorizados como insetos. 
TABELA 1: Classificação dos animais tratados no estudo pelos 50 informantes do Ribeirão da Ilha, Ilha de Santa Catarina/SC. *Animal não reconhecido a partir da imagem fornecida.

\begin{tabular}{|c|c|c|c|c|c|}
\hline \multicolumn{6}{|c|}{ Categorias de Classificação (\%) } \\
\hline Animais & Inseto & $\begin{array}{c}\text { Não } \\
\text { Inseto }\end{array}$ & $\begin{array}{l}\text { Não } \\
\text { sabe }\end{array}$ & $\begin{array}{l}\text { Bicho/ } \\
\text { Animal }\end{array}$ & $\begin{array}{l}\text { Não reco- } \\
\text { nheceu* }\end{array}$ \\
\hline Abelha & 60 & 04 & 04 & 12 & 20 \\
\hline Barata & 78 & 04 & 02 & 12 & 04 \\
\hline Besouro & 56 & 12 & 02 & 16 & 14 \\
\hline Bicho frade & 56 & 06 & 02 & 08 & 28 \\
\hline Bicho-pau & 66 & 06 & 06 & 14 & 08 \\
\hline Borboleta & 46 & 32 & 02 & 20 & - \\
\hline Cigarra & 30 & 38 & 10 & 18 & 04 \\
\hline Cupim & - & - & - & - & 100 \\
\hline Esperança & 50 & 20 & 04 & 18 & 08 \\
\hline Formiga & 58 & 02 & - & 08 & 32 \\
\hline Gafanhoto & 26 & 06 & - & 10 & 58 \\
\hline Joaninha & 24 & 06 & 06 & 06 & 58 \\
\hline Lagarta & 60 & 12 & 02 & 12 & 14 \\
\hline Libélula & 34 & 20 & 08 & 12 & 26 \\
\hline $\begin{array}{l}\text { Louva-a- } \\
\text {-deus }\end{array}$ & 56 & 08 & 02 & 12 & 22 \\
\hline Marimbondo & 50 & - & $=$ & 10 & 40 \\
\hline Mosca & 78 & - & - & 14 & 08 \\
\hline Paquinha & 22 & 20 & 04 & 08 & 46 \\
\hline Pernilongo & 58 & - & - & 02 & 40 \\
\hline Aranha & 82 & - & - & 14 & 04 \\
\hline Cobra & 50 & 26 & 04 & 20 & - \\
\hline Escorpião & 46 & 04 & 06 & 14 & 30 \\
\hline Lagarto & 12 & 34 & 08 & 20 & 26 \\
\hline Minhoca & 08 & 10 & 02 & 06 & 74 \\
\hline Morcego & 32 & 24 & 12 & 14 & 18 \\
\hline $\begin{array}{l}\text { Piolho-de- } \\
\text {-cobra }\end{array}$ & 14 & 08 & 04 & 02 & 72 \\
\hline Rato & 52 & 24 & 02 & 16 & 06 \\
\hline Tatuzinho & 18 & 04 & 02 & 08 & 68 \\
\hline
\end{tabular}

A aranha, entre todos os animais representados nas 28 imagens utilizadas, foi o animal classificado como inseto com a maior frequência entre os informantes, $82 \%$ (41). No povoado de Pedra Branca/BA, a aranha também é considerada um inseto (Costa-Neto, 2002; Costa-Neto e Pacheco, 2004; Costa-Neto, 2006). Este mesmo tipo de classificação ocorre também na comunidade de Olhos d'Água, no município de Cabaceiras do Paraguaçu/BA
(Silva e Costa-Neto, 2004). Martins (1994), realizando um estudo sobre o folclore no arquipélago dos Açores, constatou este mesmo tipo de classificação para as aranhas, o que pode indicar a influência dos nossos colonizadores na organização do nosso conhecimento.

TABELA 2: Tipos de percepções para com os animais tratados nesta pesquisa pelos 50 informantes do Ribeirão da Ilha, Ilha de Santa Catarina/SC. *Animal não reconhecido a partir da imagem fornecida.

\begin{tabular}{|c|c|c|c|c|c|}
\hline \multicolumn{6}{|c|}{ Percepção (\%) } \\
\hline Animais & Positiva & Negativa & Neutra & Respeito & $\begin{array}{l}\text { Não reco- } \\
\text { nheceu* }\end{array}$ \\
\hline Abelha $^{1}$ & 36 & 54 & 04 & 04 & 20 \\
\hline Barata & - & 96 & - & - & 04 \\
\hline Besouro $^{1}$ & 08 & 44 & 36 & - & 14 \\
\hline Bicho frade ${ }^{1}$ & - & 66 & 10 & - & 28 \\
\hline Bicho-pau & - & 74 & 18 & - & 08 \\
\hline Borboleta $^{1}$ & 92 & 02 & 08 & - & - \\
\hline Cigarra & 96 & - & - & - & 04 \\
\hline Cupim & - & - & $=$ & - & 100 \\
\hline Esperança & 80 & 02 & 10 & - & 08 \\
\hline Formiga $^{1}$ & 06 & 56 & 06 & 02 & 32 \\
\hline Gafanhoto & 04 & 30 & 08 & - & 58 \\
\hline Joaninha & 14 & 04 & 24 & - & 58 \\
\hline Lagarta $^{1}$ & 02 & 66 & 20 & - & 14 \\
\hline Libélula & 28 & 08 & 38 & - & 26 \\
\hline $\begin{array}{l}\text { Louva-a- } \\
\text {-deus }{ }^{1}\end{array}$ & 10 & 48 & 22 & - & 22 \\
\hline Marimbondo & - & 60 & - & - & 40 \\
\hline Mosca & - & 92 & - & - & 08 \\
\hline Paquinha & 48 & 02 & 04 & - & 46 \\
\hline Pernilongo & - & 56 & 04 & - & 40 \\
\hline Aranha $^{1}$ & - & 92 & 02 & 04 & 04 \\
\hline Cobra $^{1}$ & - & 94 & 02 & 08 & - \\
\hline Escorpião $^{1}$ & - & 66 & 06 & - & 30 \\
\hline Lagarto $^{1}$ & 32 & 08 & 34 & 02 & 26 \\
\hline Minhoca & 14 & 04 & 08 & - & 74 \\
\hline Morcego & 02 & 72 & 08 & - & 18 \\
\hline $\begin{array}{l}\text { Piolho-de- } \\
\text {-cobra }\end{array}$ & 02 & 10 & 16 & - & 72 \\
\hline Rato & 02 & 88 & 04 & - & 06 \\
\hline Tatuzinho & 08 & 04 & 20 & - & 68 \\
\hline
\end{tabular}

${ }^{1}$ Animais cuja soma das percepções é superior a $100 \%$, pois alguns informantes disseram percebe-los de diferentes maneiras de acordo com a situação em que os encontram. 
Tanto a minhoca (Haplotaxida) quanto o piolhode-cobra (Diplopoda) e o tatuzinho (Isopoda) não foram reconhecidos por $74 \%$ (37), $72 \%$ (36) e $68 \%$ (34) dos informantes, respectivamente (Tabela 1). O que pode ter acontecido é que as imagens destes animais utilizadas durante as entrevistas podem ter descaracterizado-os, influenciando no não reconhecimento dos mesmos. Esta situação não era a esperada, pois nas entrevistas piloto quando as imagens foram testadas isto não ocorreu.

Metade dos informantes, $50 \%$ (25), classificou o lagarto (Sauria) bicho/animal não inseto, e 44\% (22) deles também qualificaram o morcego de maneira similar.

Assim, de acordo com os informantes do Ribeirão da Ilha, dentre os 28 animais investigados nesse estudo a etnocategoria inseto é formada por 16 animais: abelha, barata, besouro, bicho frade, bicho-pau, esperança, formiga, lagarta, louva-a-deus, marimbondo, mosca, pernilongo, aranha, cobra, escorpião e rato. $\mathrm{E}$, de acordo com as sensações descritas pelos mesmos ao se deparar com estes animais, pode-se afirmar que existe uma tendência de que os animais que fazem parte da etnocategoria inseto sejam aqueles percebidos negativamente pela maioria (Tabela 2). Esta definição popular do termo inseto, que une animais considerados nojentos, transmissores de doenças e perigosos, também já foi caracterizada por Costa-Neto (2004).

\section{Usos relacionados aos insetos}

Na segunda e terceira parte do roteiro de entrevistas, os informantes foram questionados sobre quaisquer usos que pudessem ser associados com os insetos. Na segunda etapa obteve-se 15 citações de usos, proveniente de 15 informantes distintos, sendo 14 mulheres e um homem. Os demais 35 informantes disseram não conhecer nenhum uso aplicado aos insetos. Estas citações relacionavam os insetos abelha, barata, borboleta, formiga, paquinha e piolho com três categorias de usos, sendo elas: alimentação humana, decoração e medicinal (Figura 1).

No entanto, na terceira parte do roteiro, onde foram observadas as 28 figuras de animais, os informantes recordaram de outros usos dados aos insetos (Figura 2).

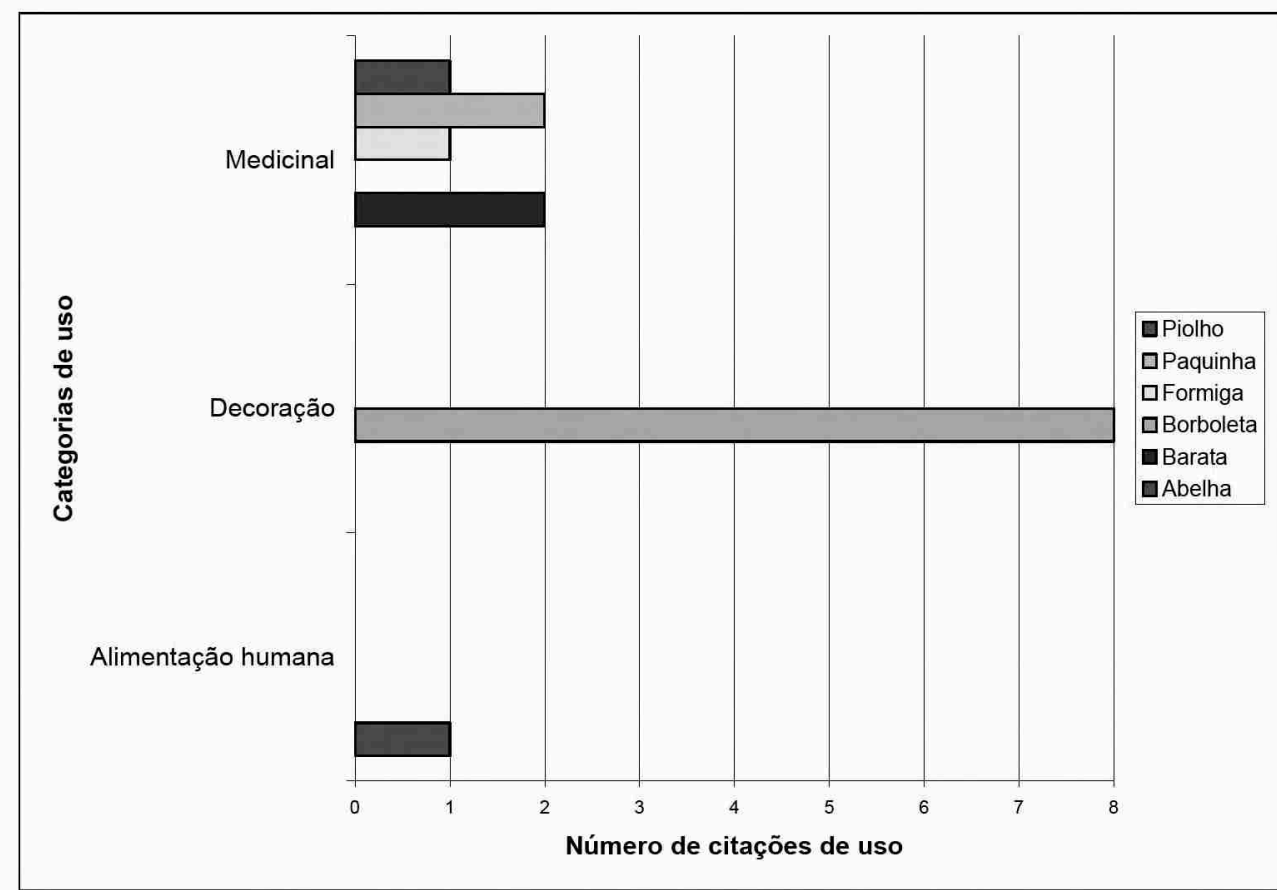

FIGURA 1: Categorias de uso para seis insetos e o número de citações de uso durante a segunda etapa da entrevista (etapa de caracterização do grupo dos insetos), com 15 informantes do Ribeirão da Ilha, Ilha de Santa Catarina/SC. 
Obteve-se então 83 citações de uso, relacionando abelha, borboleta, cigarra, cupim, formiga, gafanhoto, joaninha, libélula, paquinha e vaga-lume com sete categorias de uso, como: alimentação humana, alimento para outros animais, brincadeira, decoração, previsão do tempo, medicinal e venda. Mesmo não estando entre as 28 figuras, sete informantes disseram utilizar o vagalume em suas brincadeiras na infância.

É importante destacar que todos os informantes relataram que a maior parte dos usos relacionados aos insetos foi praticada somente durante sua infância e mocidade. Hoje utilizam apenas o mel para a alimentação, a picada de abelha para curar reumatismos e a borboleta para decoração.

Observando a segunda e a terceira parte do roteiro juntas (98 citações de usos) pode-se afirmar que, neste grupo amostral formado por 35 mulheres e 15 homens, o conhecimento quanto aos usos dos insetos não está restrito ao sexo dos informantes ou a alguma faixa etária. Isto porque todas as informantes mulheres citaram, no mínimo, um uso para um inseto e dos 15 informantes homens, 12 mencionaram algum uso enquanto que apenas três não souberam fazê-lo.

No total, 12 animais tiveram citações de usos: abelha, barata, borboleta, cigarra, cupim, formiga, gafanhoto, joaninha, libélula, paquinha, piolho e vagalume.

As citações de uso dos insetos foram analisadas quanto à fidedignidade (FL) e prioridade de ordenamento (ROP). O FL retrata o grau de correspondência entre as respostas dos informantes quanto aos usos citados para um animal. Por exemplo, o cupim apresentou FL igual a 100 , pois todos os informantes, dentre aqueles que reconheceram algum uso, descreveram o mesmo uso para este animal. Já a libélula apresentou o FL mais baixo, pois cada informante citou um uso diferente para este inseto (Tabela 3 ).

Esta análise nos permitiu identificar que os usos mais frequentes na comunidade estão relacionados

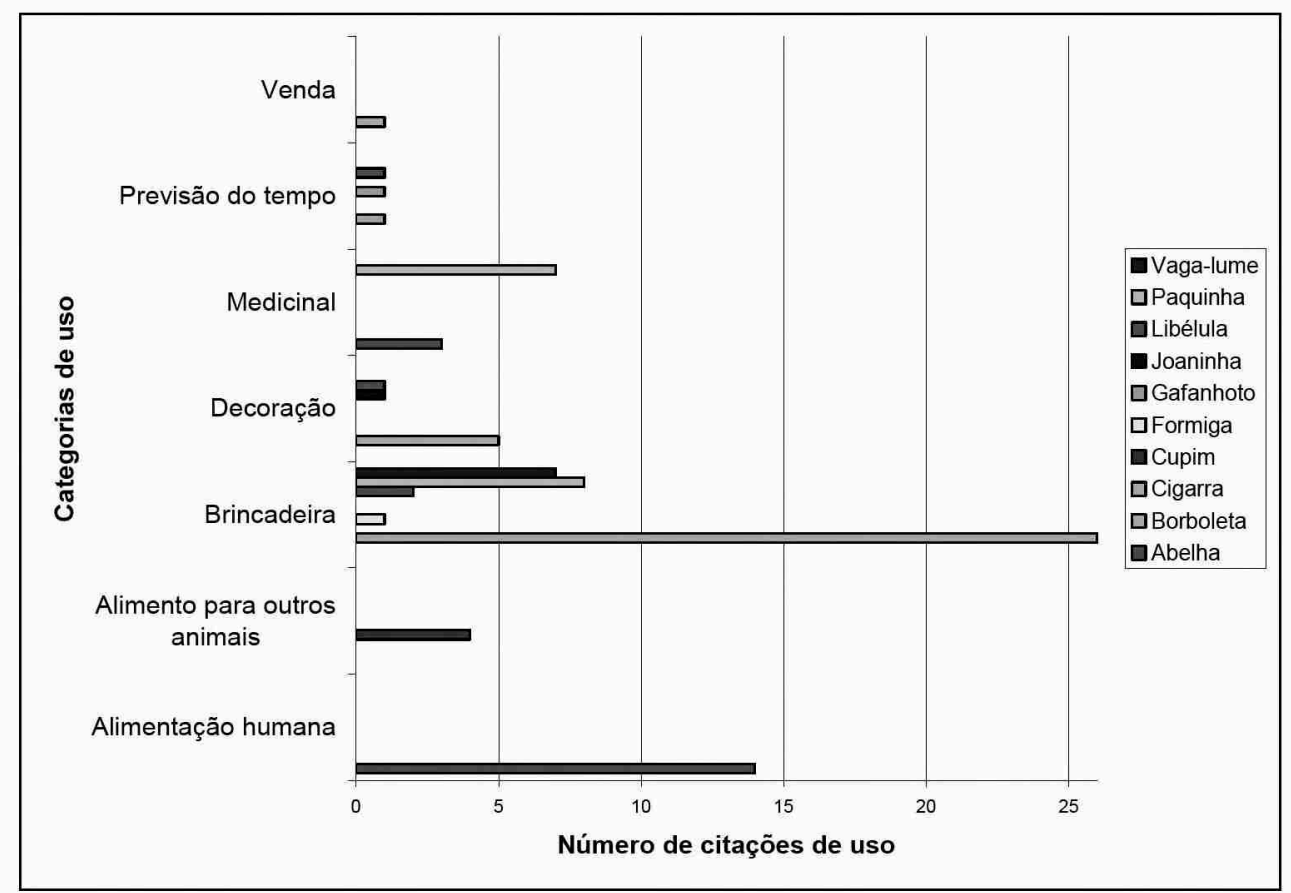

FIGURA 2: Categorias de uso para dez insetos e o número de citações de uso durante a terceira etapa da entrevista (etapa de observação de 28 imagens de animais), com 47 informantes do Ribeirão da Ilha, Ilha de Santa Catarina/SC. 
com os costumes dos informantes de utilizar insetos em suas brincadeiras (cigarra), como recurso medicinal (paquinha), decorativo (borboleta) e alimentício (mel da abelha).

TABELA 3: Nível de fidedignidade entre as respostas sobre usos dos insetos e prioridade de ordenamento destes usos, para 50 informantes do Ribeirão da Ilha, Ilha de Santa Catarina/SC. FL - Nível de Fidedignidade. ROP - Prioridade de Ordenamento.

\begin{tabular}{cccc}
\hline INSETOS & FL & ROP & USO PRINCIPAL \\
\hline Cigarra & 96,30 & 97 & Brincadeira \\
Paquinha & 53,00 & 63 & Medicinal \\
Borboleta & 93,00 & 56 & Decorativo \\
Abelha & 83,33 & 55 & Alimentação humana \\
Vaga-lume & 100,00 & 26 & Brincadeira \\
Cupim & 100,00 & 15 & Alimento para outros \\
Libélula & 50,00 & 15 & animais \\
Barata & 100,00 & 07 & Brincadeira \\
Formiga & 100,00 & 07 & Brincadicinal \\
Gafanhoto medicinal* & 100,00 & 04 & Previsão do tempo \\
Joaninha & 100,00 & 04 & Decorativo \\
Piolho & 100,00 & 04 & Medicinal \\
\hline
\end{tabular}

*Os dois usos apresentaram o mesmo número de citações, $n=1$.

\section{a) Insetos e alimentação}

Como podem ser observados pelos depoimentos abaixo, os animais relacionados com a alimentação foram: abelha, lagarto e cupim.

"A abelha é boa, ela faz o mel que faz bem pra gente" (L., 65 anos).

"A carne do lagarto é boa. Só tem que tomar cuidado quando preparar. A gente deve deixar do dia pra noite de vinha d'alho. Se amanhecer e a carne estiver roxa, é porque ela tá contaminada pelo veneno da cobra. Se tiver branquinha, pode come" (P., 64 anos).

"O cupim, esse do mato, daqueles cupinzeiro alto, serve pra alimenta pato, peru, pintinho e curió" (C., 76 anos).

O lagarto não faz parte da etnocategoria inseto por ter sido considerado como tal por apenas seis dos 50 informantes. Porém, seu uso na alimentação é retratado por ter sido descrito por um dos seis informantes que o consideraram inseto.
Já o cupim, mesmo não sendo reconhecido por todos os informantes, é utilizado por um deles para alimentar sua criação de pato e curió.

Com relação à abelha, que faz parte da etnocategoria inseto dos informantes, o mel foi considerado apenas como recurso alimentar. Na comunidade de Remanso/ BA, o mel, além de alimento, foi registrado como um importante recurso medicinal para combater tosses e resfriados (Costa-Neto, 2000b). No estado de Alagoas, o mel foi caracterizado também como remédio contra sapinho (micose), verminoses, caxumba, tuberculose, dor de cabeça, catarata, vista curta, fraqueza nos nervos, hemorragia após o parto e câncer (Costa-Neto e Marques, 2000). Nomura (2001), além de registrar o consumo de mel de abelha pelos índios da Serra do Norte, descreve que estes apreciam as larvas das abelhas mergulhadas no própolis ou no próprio mel.

\section{b) Insetos na medicina popular}

Os informantes disseram que durante a infância, em uma época caracterizada pela grande dificuldade para se obter remédios prontos, observavam os "mais velhos" utilizarem diversas plantas e animais como remédios, com o intuito de combater uma série de doenças.

Dentre as doenças tratadas estão o reumatismo, com picada da abelha; a bronquite e o sarampo, com barata; problemas de visão, com formiga; problemas para firmar as pernas e o pescoço de crianças e curar bronquite, com paquinha; a asma ou canseira, com piolho. O modo como eram preparados os remédios seguem descritos abaixo:

"Barata servia contra bronquite. A gente torrava a barata, fazia farelo e misturava no leite pra tomá pra ficar bom" (A., 76 anos) e "O chá da barata seca servia pra livrá do sarampo" (P., 64 anos).

"Formiga, aquela do açúcar, faz bem pras vista" (Z., 64 anos).

"Pra endurecer as perninhas das crianças que tão custando a andar, a gente passa a paquinha nas perninhas delas. Depois solta a paquinha de novo na praia. Cada dia se passa uma paquinha nova e as perninhas endurecem. A criança vai anda ligeiro. Serve também pra firmar o pescoçinho das crianças" (N., 60 anos) e "A gente fazia o tali do bebe com a paquinha pra 
curá bronquite. A gente faz uma mistura com a paquinha e põe ela dentro de um paninho que é amarrado num cordão. Adepois, põe o cordão no pescoço, anda com ele que sara" (M., 84 anos).

"Pra asma ou canseira a gente fazia um remédio com piolho. Secava o piolho e fazia um chá pra beber" (Q., 77 anos).

O estudo de Costa-Neto e Marques (2000), realizado em Alagoas, registra o uso medicinal de abelha, barata, barbeiro/percevejo, besouro, cupim, formiga, grilo, lagarta, libélula, mosca e vespa. Tanto a barata quanto a formiga são utilizadas, em Alagoas, contra males distintos dos relatados pelos informantes do Ribeirão da Ilha. Enquanto que no Ribeirão da Ilha a barata é utilizada para tratar sarampo, em Alagoas a barata inteira é usada para tratar enfermidades localmente relatadas como dor de cólica, dor de barriga, asma, alcoolismo e epilepsia. Alves e Rosa (2007) estudando comunidades nos Estados do Pará, Maranhão, Piauí e Paraíba também relatam o uso da barata no tratamento da asma.

No Ribeirão da Ilha, a formiga é utilizada para melhorar a visão. Em Alagoas, a picada deste inseto é usada para tratar impotência e verruga. Já na comunidade de Bom Sucesso/PB, a formiga é usada para tratar dor de garganta (Alves et al., 2008).

\section{c) Insetos e meteorologia}

Três superstições ligadas à previsão do tempo também foram registradas. Cada uma foi associada a um inseto: cigarra, gafanhoto e libélula. Cabe ressaltar que a libélula é reconhecida pelos informantes com o nome de zorro ou besouro.

"Quando a cigarra de guizo canta pela manhã, está anunciando trovoada para de tarde" (A.M., 57 anos), "Quando aparece um monte de gafanhoto quer dizê que o tempo tá pra mudá pra chuva ou pra vento sul" (C., 62 anos) e "Besouro (libélula) quando muito, marca que o tempo quente tá vindo do sul” (V., 72 anos).

Lenko e Papavero (1996) historiam que Moura, em 1910, realizando um estudo pelo Vale do Rio Tocantins, registrou que o canto pronunciado da cigarra é o prenúncio para um crepúsculo morno. Estes mesmos autores retratam também superstições com formiga associadas à previsão do tempo: "formiga quando carrega o ovo pra fora do formigueiro é sinal de tempestade e tempo chuvoso", "muita terra na borda do formigueiro indica chuva" e "formiga de roça quando abre formigueiro nas baixadas e leitos de rios significa que o ano será seco".

Marconi (1963 apud Lenko e Papavero, 1996) relata que na região de Urucum, município de Corumbá/ MS, para acabar com um temporal bravo queima-se a casa do cupim: "quando está chovendo muito, e se deseja espantá a chuva, é só derrubar um pedaço do cupim no chão, que logo os bichinhos começam a chorar e pedir a Deus para a chuva parar e o sol vir de novo".

Martins (1994) não registrou a utilização de insetos sob o ponto de vista da classificação científica para se prever o tempo pelos moradores do arquipélago dos Açores. Todavia, relatou este uso para piolho-decobra (Diplopoda) e centopéia (Chilopoda), ambos considerados insetos pelos moradores do arquipélago. Estes animais, quando encontrados em alguma parede da casa, anunciavam que o tempo estava para mudar. Costa-Neto (2007) descreveu que os moradores do povoado de Pedra Branca/BA relacionam o aparecimento de diplópodos com a ocorrência de chuva na região.

\section{d) Insetos como elementos decorativos}

Tanto a borboleta quanto a joaninha e a libélula, na comunidade do Ribeirão da Ilha, foram caracterizadas como elementos decorativos de festas de aniversário de crianças, enfeites para casa compondo quadros, portas retratos, toalhas e colchas, entre outros.

"Quando eu era pequena, pegava as borboletas, aquelas azuis bem grandes e bonitas, e pregava elas na parede pra enfeitar a casa" (D., 84 anos) e "Borboleta, libélula e joaninha a gente usa pra fazer decoração de festinha de criança" (A., 53 anos).

Pagaza-Calderón et al. (2006) também registram o uso ornamental de lepidópteros adultos em Tlacuilotepec, no estado de Puebla (México). Nomura (2001) afirma que devido aos diversos coloridos, os lepidópteros são muito procurados para adorno, assim como os coleópteros que apresentam cor metálica. 


\section{e) Uso lúdico dos insetos}

Os informantes relataram utilizar adultos de diferentes ordens, como a cigarra, a formiga, a libélula, a paquinha e o vaga-lume para brincar. Posey (1987b) registrou o papel desempenhado pelos insetos na vida recreativa de diferentes sociedades, servindo como brinquedos, participando de atividades circenses, entre outras atividades lúdicas.

Os informantes do Ribeirão da Ilha, quando crianças, brincavam de ouvir o canto das cigarras. A brincadeira envolvia, primeiramente, a captura da cigarra que depois era amarrada e pendurada por uma linha no interior das casas para entoar seu canto: "Na época de novembro até janeiro, a gente pegava as cigarras, amarrava suas perninha numa linhazinha que ficava presa numa cadeira ou na árvore de Natal pra ouvir elas cantar" (E., 76 anos).

As libélulas eram utilizadas nas brincadeiras de "aviãozinho". Para capturar estes insetos os informantes relataran que: "a gente pegava elas com um puçá que era feito de verga de bambu e coador de café na ponta" (O., 63 anos).

Em Alagoas, no povoado de Quebrangulo, as crianças contaram fazer estas mesmas brincadeiras com as cigarras, e no povoado de Marituba do Peixe, as crianças contaram brincar também com as libélulas, não descrevendo suas brincadeiras (Costa-Neto e Marques, 2000). Tanto as crianças dos dois povoados em Alagoas (Costa-Neto e Marques, 2000) quanto os informantes deste estudo afirmaram divertir-se também com formigas e vaga-lumes:

"Brincava de botá as formigas pra brigar uma com as outras" (E., 76 anos).

"Quando já tava escurecendo a gente pegava o vagalume colocava preso em pote de vidro pra ilumina a casa. Ele ficava com os olhos acesos" (C., 76 anos).

Lenko e Papavero (1996) registraram os folguedos infantis em diversas regiões brasileiras sobre os vagalumes, assim como Neves (1957) o fez para a região de Vitória/ES. Um dos informantes do Ribeirão da Ilha narrou um folguedo que era muito cantado pelas crianças da época na hora em que estavam capturando os vaga-lumes:

"Vaga-lume, vai, vai, que teu pai já vem. Vaga-lume vai, vaga-lume vem” (A., 68 anos).

Observou-se também a utilização de paquinhas nas atividades lúdicas das crianças.

"Brincava de segui o carreirinho da paquinha na praia pra mexê com ela" (H., 69 anos).

Estes insetos pertencem à família Gryllotalpidae. Lenko e Papavero (1996) registram este tipo de brincadeira com as paquinhas, também conhecidas por grilos-toupeira, em outras regiões do Brasil.

\section{f) Insetos na economia local}

Uma história registrada durante a entrevista de C. (87 anos), relata a obtenção de dinheiro com a venda de borboletas:

"Já peguei muita borboleta pra vendê. A gente, eu e meus irmãos, pegava as borboletas, várias delas, e alfinetava certinho no tronquinho delas onde o moço nos ensinou. Depois a gente colocava elas numa caixinha que ele nos deu. Passado um tempo o moço voltava pra comprar elas e também os couros dos lagartos que a gente tirava. Ele dizia que fazia sapato com o couro do lagarto. Isso era quando eu tinha uns seis anos, lá pra 1928. Eu acho que ele era estrangeiro, pois falava um português bem carregado" (C., 85 anos).

A história retratada acima pode nos remeter ao questionamento de quem poderia ser o estudioso, naturalista ou colecionador que na década de 20 andava pela região do Ribeirão da Ilha coletando borboletas.

Muitos viajantes naturalistas do velho mundo visitaram o sul do Brasil, entre eles destaca-se o Barão Georg Heinrich Von Langsdorff, médico alemão que navegou ao redor do mundo e, em 20 de dezembro de 1803, chegou a Ilha de Santa Catarina onde permaneceu estudando e colecionando principalmente espécimes da fauna até fevereiro de 1804 (Haro, 1996). Durante sua permanência na Ilha fez o seguinte relato:

"Muitas excursões ainda fizemos juntos, mas de todas tenciono relatar uma que fizemos ao lugar de montanha chamado 'Sertão das picadas', onde existe um grande Rio de nome Ribeirão, a uma distância de duas milhas 
e meia para o interior. Conforme me assegurou meu guia, este seria o local onde estariam as maiores e melhores borboletas, entre elas, especialmente a Papil. Adonis Crameri, Pap. Epistrophus Weber, Pap. Helenor. Cram., P. Lysimnia, P. Februa Hoffmanseggi, P. Thoas, P. Archidamas e muitas outras que me despertam a curiosidade."

Carrera (1982) afirma que no Brasil, os insetos, especialmente as borboletas do gênero Morpho, de asas azuis muito brilhantes, têm sido exportadas desde o período colonial, época quando muitos cronistas, viajantes e historiadores naturais registraram as impressões nativas sobre o meio ambiente. Góes (2004) afirma que pratinhos, bandejas, biombos e tampos de mesas decorados com um inconfundível azulmetálico, tornaram-se produtos típicos de um rentável comércio internacional de asas de borboletas onde o Brasil mostra-se como uma fonte de maravilhosos suprimentos.

Pelos dados ora apresentados, pode-se afirmar que na comunidade do Ribeirão da Ilha (SC, Brasil) a etnocategoria inseto é formada por 16 animais - abelha, barata, besouro, bicho frade, bicho-pau, formiga, esperança, lagarta, louva-a-deus, marimbondo, mosca, pernilongo, aranha, cobra, escorpião e rato - e, majoritariamente, é constituída por animais percebidos negativamente pela população, isto é, que causam sensações de medo, nojo, agonia e irritação nas pessoas; que sabidamente ocasionam algum problema de saúde e que danificam as plantas do jardim ou a roça. Além disso, todos os informantes souberam descrever pelo menos um uso para algum inseto. De modo geral, os insetos estão ligados ao uso lúdico (brincadeiras), decorativo, alimentício (tanto humana quanto para a criação de outros animais), medicinal, à previsão do tempo e à obtenção de dinheiro (venda). Destaca-se ainda que a maior parte dos usos aqui descritos não são mais praticados na comunidade já que os informantes relataram tê-los realizado somente durante sua infância e mocidade. Atualmente, apenas três usos são praticados pela comunidade: consumo de mel na alimentação, picada de abelha para curar reumatismos e borboleta para decoração.

\section{Agradecimentos}

Aos moradores do Barro Vermelho, Freguesia do Ribeirão da Ilha e Costeira do Ribeirão que aceitaram participar deste trabalho cedendo parte de seu tempo e conhecimentos, aos motoristas da UFSC e à PROINFRA - Pró Reitoria de Infraestrutura/UFSC.

\section{Referências}

Albuquerque, U. P. de; Lucena, R. S. P. de. 2004. Métodos e técnicas para coleta de dados. In: Albuquerque, U. P. de; Lucena, R. S. P. de. (Coords). Métodos e técnicas na pesquisa etnobotânica. Livro Rápido/NUPEEA, Recife, Brasil, p.37-62.

Alves, R. R. N.; Rosa, I. L. 2007. Zootherapeutic practices among fishing communities in North and Northeast Brazil: a comparison. Journal of Ethnopharmacology, 111: 82-103.

Alves, R. R. N.; Soares, T. C.; Mourão, J. da S. 2008. Uso de animais medicinais na Comunidade de Bom Sucesso, Soledade, Estado da Paraíba, Brasil. Revista Sitientibus, Série Ciências Biológicas, 8 (2): 142-147.

Carrera, M. 1982. Nota sobre insetos utilizados como adorno. Revista Brasileira de Entomologia, 26 (1): 133-135.

Cereto, C. E.; Lopes, B. C. 2008. Ambivalência entomoprojetiva e o conhecimento popular sobre insetos de moradores do Pântano do Sul, Florianópolis, SC, Sul do Brasil. Anais do XXVI Congresso Brasileiro de Zoologia, Curitiba Paraná, Brasil, p.1856.

Costa-Neto, E. M. 2000a. O homem e os insetos: a perspectiva etnoentomológica. Introdução à etnoentomologia: considerações metodológicas e estudo de casos. UEFS, Feira de Santana, Brasil, p.21-36.

Costa-Neto, E. M. 2000b. Conhecimento e usos tradicionais de recursos faunísticos por uma comunidade Afro-brasileira Resultados preliminares. Interciência, 25 (9): 423-431.

Costa-Neto, E. M. 2002. Manual de Etnoentomología. Volume 100. Editora Zaragoza, Sociedad Entomológica Aragonesa, Zaragoza, España, 104pp.

Costa-Neto, E. M. 2004. Os insetos que ofendem: Artrópodes na visão dos moradores da região da Serra da Jibóia, Bahia, Brasil. Revista Sitientibus, Série Ciências Biológicas, 4 (1/2): 59-68.

Costa-Neto, E. M. 2005. O "Louva-a-Deus-de-cobra", Phibalosoma sp. (Insecta, Phasmida), segundo a percepção dos moradores de Pedra Branca, Santa Terezinha, Bahia, Brasil. Revista Sitientibus, Série Ciências Biológicas, 5 (1): 33-38.

Costa-Neto, E. M. 2006. Bird-spiders (Arachnida, Mygalomorphae) as perceived by the inhabitants of the village of Pedra Branca, Bahia State, Brazil. Journal of Ethnobiology and Ethnomedicine, 2: 1-19.

Costa-Neto, E. M. 2007. The perception of Diplopoda (Arthropoda, Myriapoda) by the inhabitants of the county of Pedra Branca, Santa Teresinha, Bahia, Brazil. Acta Biologica Colombiana, 12 (2): 123 134.

Costa-Neto, E. M.; Marques, J. G. W. 2000. Notas de etnoentomologia no estado de Alagoas, com ênfase na utilização 
medicinal de insetos. In: Introdução à etnoentomologia: Considerações metodológicas e estudo de casos. UEFS, Feira de Santana, Brasil, p.83-97.

Costa-Neto, E. M.; Pacheco, J. M. 2004. A construção do domínio etnozoológico "inseto" pelos moradores do povoado de Pedra Branca, Santa Terezinha, Estado da Bahia. Acta Scientiarum Biological Sciences, 26 (1): 81-90.

D’Olne Campos, M. 2002. Etnociência ou etnografia de saberes, técnicas e práticas? Anais do Seminário de Etnobiologia e Etnoecologia do Sudeste, Rio Claro, Brasil, p.47-92.

Ellen, R. 1997. Indigenous knowlodge of the rainforest: Perception, extraction and conservation. Disponível em $<\mathrm{http} / /$ www.lucy.ukc.ac.uk/malon.html>. Acesso em 20 de outubro de 2007

Friedman, J.; Yaniv, Z.; Dafni, A.; Palewitch, D. 1986. A preliminary classification of the healing potential of medicinal plants, based on a rational analysis of an ethnopharmacologlcal field survey among Bedouins in the Negev Desert, Israel. Journal of Ethnopharmacology, 16: 275-287.

Góes, R. de. 2004. Os duendes de seis patas e a Cidade Mutante: o lado mágico da natureza na São Pulo dos anos 50. Geração Editorial, São Paulo, Brasil, 174pp.

Goodenough, W. H. 2003. In pursuit of culture. Annual Review of Anthropology, 32: 1-12.

Gullan, P. J.; Cranston, R. S. 2008. The insects: an outline of entomology. Blackwell Science, Oxford, UK, 470pp.

Haro, M. A. 1996. Ilha de Santa Catarina: relatos de viajantes estrangeiros nos séculos XVIII e XIX. UFSC, Florianópolis, Santa Catarina, Brasil, 334pp.

IBGE - Instituto Brasileiro de Geografia e Estatísticas. 2000. Sistema IBGE de recuperação automática (SIDRA), censo demográfico e contagem de 2000. Disponível em <http: //www. sidra.ibge.gov.br/>. Acesso em 19 de julho de 2009

IPUF - Instituto de Planejamento Urbano de Florianópolis. 2007. Informações dstritais, Distrito do Ribeirão da Ilha. Disponível em $<$ http://www.ipuf.sc.gov.br/pdp/informacoesdi stritais/ribeiraodailha.pdf $>$.

Lenko, K.; Papavero, N. 1996. Insetos no folclore. Plêiade e FAPESP, São Paulo, Brasil, 468pp.

Longo, P. L.; Pires, J. S. R. 1998. Análise da percepção em relação à fauna encontrada próxima ou dentro das casas de estudantes de diferentes localidades - São Paulo, São Carlos e Água Vermelha. Anais do Simpósio Brasileiro de Etnobiologia e Etnoecologica, São Carlos, Brasil, p.113.
Martins, J. H. B. 1994. Crenças populares da Ilha Terceira II Alma do outro mundo, o diabo, encantados e varia. Salamandra, Lisboa, Portugal, 124pp.

Minayo, M. C. de S. 2003. Ciência, técnica e arte: o desafio da pesquisa social. In: Minayo, M. C. de S. (Org.). Pesquisa social: Teoria, método e criatividade. Vozes, Petrópolis, Brasil, p.9-30.

Navarijo, M. L. 2006. Percepciones e importância de los insectos em el âmbito urbano de la Ciudad de México, México. Revista Sitientibus, Série Ciências Biológicas, 6 (4): 334-342.

Neves, G. S. 1957. Vaga-lume, lume, lume. Jornal A gazeta, Vitória, Espírito Santo, Brasil. Disponível em $<\mathrm{http} / / \mathrm{www}$. jangadabrasil.com.br/revista/marco88/es8800305.asp >. Acesso em 01 de agosto de 2009.

Nomura, H. 2001. Curiosidades folclóricas sobre os insetos. Caderno de Folclore, 12. Centro de Estudos da Cultura Popular, Prefeitura Municipal de São José dos Campos, São José dos Campos, Brasil, 40pp.

Pagaza-Calderón, E. M.; González-Insuasti, M. S.; PachecoOliveira, R. M.; Pulido, M. T. 2006. Importancia cultural, en función del uso, de cinco especies de artrópodos en Tlacuilotepec, Puebla, México. Revista Sitientibus, Série Ciências Biológicas, 6 (Especial - Etnoentomologia): 65-71.

Posey, D. A. 1987a. Introdução: Etnobiologia, teoria e prática. In: Ribeiro, D. (Ed.). Suma entomológica brasileira. Edição atualizada do Handbook of South American indians. Etnobiologia, 1. $2^{\text {a }}$ ed. Vozes/Finep, Petrópolis, Brasil, p.15-25.

Posey, D. A. 1987b. Etnoentomologia de tribos indígenas da Amazônia. In: Ribeiro, D. (Editor). Suma Entomológica Brasileira. Edição atualizada do Handbook of South American Indians. Etnobiologia, 1: 251-272. Vozes/Finep, Petrópolis, Brasil.

Quivy, R.; Campenhoudt, L. V. 1992. Manual de investigação em Ciências Sociais. Gradiva, Lisboa, Portugal, 282pp

Silva, T. F. P.; Costa-Neto, E. M. 2004. Percepção de insetos por moradores da comunidade de Olhos d'Água, município de Cabaceiras do Paraguaçu, Bahia, Brasil. Boletim da Sociedade Entomológica Aragoneza, 35: 261-268.

Triplehorn, C. A.; Johnson, N. F. 2005. Borror and DeLong's Introduction to the study of insects. Thomson Brooks/Cole, Belmont, California, USA, 864pp 